\title{
Increase of neuronal injury markers Tau and neurofilament light proteins in umbilical blood after intrapartum asphyxia
}

\author{
Hanna Toorell ${ }^{1}$, Henrik Zetterberg ${ }^{2,3,4}$, Kaj Blennow ${ }^{2,3}$, Karin Sävman ${ }^{5}$, and Henrik \\ Hagberg ${ }^{1,6^{*}}$
}

${ }^{1}$ Perinatal Center, Institute of Clinical Sciences, Sahlgrenska Academy, University of Gothenburg, Sweden;

${ }^{2}$ Clinical Neurochemistry Laboratory, Sahlgrenska University Hospital, Mölndal, Sweden;

${ }^{3}$ Department of Psychiatry and Neurochemistry, Institute of Neuroscience and Physiology, Sahlgrenska Academy at the University of Gothenburg, Mölndal, Sweden; ${ }^{4}$ Department of Molecular Neuroscience, UCL Institute of Neurology, University College London, London, United Kingdom.

${ }^{5}$ Department of Pediatrics, Institute of Clinical Sciences, Sahlgrenska Academy, University of Gothenburg, Sweden

${ }^{6}$ Centre for the Developing Brain, Division of Imaging Sciences and Biomedical Engineering, King's College London, St. Thomas' Hospital, London, SE1 7EH, United Kingdom

* Corresponding Author:

Prof Henrik Hagberg

Email: henrik.hagberg@gu.se

Address: Perinatal Center, Sahlgrenska Academy, Sahlgrenska University HospitalEAST CAMPUS, 41685 Gothenburg, SWEDEN

Keywords: asphyxia, brain injury, biomarkers, umbilical blood

\section{Acknowledgments:}

We gratefully acknowledge the support of the Department of Perinatal Imaging and Health and financial support from Wellcome Trust (WT094823), the Swedish Medical Research Council (VR 201502493; 2013-2546), Governmental Grants to University Hospitals in Sweden (ALFGBG-426401, ALFGBG441051), Action Medical Research, ERA-net (EU;VR 529-2014-7551), the Knut and Alice Wallenberg Foundation ( $\mathrm{HZ}$ is a Wallenberg Academy Fellow), Hjärnfonden (Brain Foundation 2015-0004), the Leducq Foundation (DSRRP34404) and the Wilhelm and Martina Lundgren Foundation, to enable this study to be completed. In addition, the authors acknowledge financial support from the Department of Health via the National Institute for Health Research (NIHR) comprehensive Biomedical Research Centre Award to Guy's \& St Thomas' NHS Foundation Trust in partnership with King's College London and King's College Hospital NHS Foundation Trust. 


\section{Abstract}

\section{Introduction}

Asphyxia caused by a lack of oxygen or blood flow to the brain around the time of birth affects $1 \%$ of infants and $10-20 \%$ of these cases develop some degree of hypoxicischemic encephalopathy $[1,2]$ in the developed world whereas the occurrence is much higher in underprivileged countries [3].

Today infants suffering from moderate or severe encephalopathy are offered neuroprotective therapy with hypothermia (4) and other therapies are currently being developed (3). Therefore, there is a renewed interest in the development of biomarkers that can predict the risk of brain injury and aid in the selection of cases that should be offered therapy. Previous reports show that MRI/MRS (5) as well as multiple biochemical biomarkers in cerebrospinal fluid or neonatal blood hours to days after birth are elevated after moderate and severe asphyxia at least if there is development of HIE (6-16). However, there is a scarcity of biomarkers detectable in readily accessible body fluids such as umbilical blood early enough to be useful for directing therapy (17).

Generally, cases with asphyxia that do not develop moderate or severe encephalopathy are considered to have a good long-term prognosis $(16,18)$. However, recent studies suggest that there may be a continuum relationship between severity of asphyxia and outcome as cognitive outcome seems affected also in cases with mild encephalopathy (19) and the school performance was suboptimal in children aged 16 born with Apgar <7 at 5 min (20). Utilizing new sensitive analytical assays our aim was to explore whether the axonal brain injury biomarkers tau and neurofilament light (NFL) (Zetterberg H, Blennow K. Nat Rev Neurol. 2016 Oct;12(10):563-74) were elevated in umbilical blood at birth in cases with moderate asphyxia (Apgar $\leq 7,5 \mathrm{~min}$ and metabolic acidosis but not HIE) compared with a non-asphyxiated group of newborns.

\section{Materials and methods}

The ethical board of the Västra Götaland approved the study protocol (\#...). Informed consent was provided by all study participants.

The asphyxia participants included 12 newborns ( 6 boys, 6 girls; median gestational age: 39 weeks) with neonatal asphyxia (Apgar $\leq 7$ at $5 \mathrm{~min}$ and /or umbilical blood acidosis ( $\mathrm{pH} \leq 7.0$ ). The control group comprised 24 newborns (15 boys, 9 girls; mean gestational age 37 weeks) without neonatal asphyxia (Apgar $\geq 8$ at 5 min and umbilical cord $\mathrm{pH}>7.35$ ).

Umbilical artery and vein blood samples were routinely obtained from study 
participants through a doubly clamped segment of the umbilical cord and collected into non-heparinized $5 \mathrm{ml}$ syringes. From these samples, we measured acid base and blood gases. After centrifugation, serum samples were collected and frozen and stored at $80^{\circ} \mathrm{C}$ until the assay was performed.

NFL and tau concentrations were measured using ultrasensitive Single molecule array (Simoa) assays as previously described in detail (refs: Rohrer JD et al., Neurology. 2016 Sep 27;87(13):1329-36; Mattsson N et al., Neurology. 2016 Oct 25;87(17):1827-1835). The measurements were performed by board-certified laboratory technicians who were blinded to clinical information in one round of experiments using one batch of reagents. Lower limits of quantification were around $1 \mathrm{pg} / \mathrm{mL}$ and intra-assay coefficients of variation were below $10 \%$.

\section{Results}

The asphyxia group had a median Apgar of 3 at $1 \mathrm{~min}, 7$ at $5 \mathrm{~min}$ and 8 at $10 \mathrm{~min}$ which was significantly lower than in the control group (Table 1). The mean arterial $\mathrm{pH}$ was 6.93 and base excess -16.5 in the asphyxia group compared to 7.37 and -1.92 , respectively, in controls indicating a significant degree of hypoxia in the asphyxia group. However, none of the asphyxia cases developed any degree of hypoxicischemic encephalopathy and there was no mortality in any of the groups (check!!). The mean serum concentration of tau was $61.8 \pm 22.3 \mathrm{pg} / \mathrm{mL}( \pm \mathrm{SEM}$ ) in the asphyxia group compared to $23.2 \pm 4.3$ in the control group $(p=0.026)$. The concentration of $\mathrm{NFL}$ amounted to $62.5 \pm 23.0 \mathrm{pg} / \mathrm{mL}( \pm \mathrm{SEM})$ in the umbilical blood of the asphyxiated newborns and $25.2 \pm 2.1$ in the controls $(p=0.028)$.

\section{Discussion}

1. summarize results

2. no one measured TAU and NFL in umbilical blood before but TAU in neonatal serum and NFL in CSF and describe what they found

3 , interesting that brain injury markers are sign increased in spite of moderate degree of asphyxia and no HIE supporting that some brain injury may occur even without overt signs of HIE and also interesting that these sensitive assays could detect the low basal levels of these proteins in the serum as well as the moderate increases seen after asphyxia

4. could mean that these markers could be useful for guiding the clinician regarding neuroprotective therapy and in the future these or similar markers could be analyzed in the fetal scalp and if raised could direct the clinician whether the infant should be delivered or not. (maybe not possible to measure in $50 \mathrm{ul}$ of blood ?? and maybe not fast enough to be useful for the obstetrician - but maybe in the future) - one of the problems with the presently used $\mathrm{pH}$ and lactate is the limited specificity

5. limitations. relatively limited \# of cases and only moderately asphyxiated needs to be reproduced in a larger cohort of infants with and without different degrees of HIE.

\section{References}

1. Evans K, Rigby AS, Hamilton P, Titchiner N, Hall DM. The relationships between neonatal encephalopathy and cerebral palsy: a cohort study. J Obstet Gynaecol. 2001; 21: 114-20. 
2. Hagberg H, Edwards AD, Groenendaal F. Perinatal brain damage: The term infant. Neurobiol Dis. 2016 Aug;92(Pt A):102-12.

3. Ellis M, Manandhar N, Manandhar DS, Costello AM. Risk factors for neonatal encephalopathy in Kathmandu, Nepal, a developing country: unmatched case-control study. BMJ. 2000; 320: 1229-36.

4. Azzopardi D, Strohm B, Marlow N, Brocklehurst P, Deierl A, Eddama O, Goodwin J, Halliday HL, Juszczak E, Kapellou O, Levene M, Linsell L, Omar O, Thoresen M, Tusor N, Whitelaw A, Edwards AD; TOBY Study Group.. Effects of hypothermia for perinatal asphyxia on childhood outcomes. N Engl J Med. 2014 371(2):140-9.

5. Groenendaal F, de Vries LS. Fifty years of brain imaging in neonatal encephalopathy following perinatal asphyxia. Pediatric research. 2016.

6. Blennow M, Hagberg H, Rosengren L. Glial fibrillary acidic protein in the cerebrospinal fluid: a possible indicator of prognosis in full-term asphyxiated newborn infants? Pediatric research. 1995;37(3):260-4.

7. Blennow $M$, Savman $K$, Ilves $P$, Thoresen $M$, Rosengren $L$. Brain-specific proteins in the cerebrospinal fluid of severely asphyxiated newborn infants. Acta paediatrica. 2001;90(10):1171-5.

8. Chaparro-Huerta V, Flores-Soto ME, Merin Sigala ME, Barrera de Leon JC, Lemus-Varela ML, Torres-Mendoza BM, et al. Proinflammatory Cytokines, Enolase and S-100 as Early Biochemical Indicators of Hypoxic-Ischemic Encephalopathy Following Perinatal Asphyxia in Newborns. Pediatrics and neonatology. 2016.

9. Douglas-Escobar M, Yang C, Bennett J, Shuster J, Theriaque D, Leibovici A, et al. A pilot study of novel biomarkers in neonates with hypoxic-ischemic encephalopathy. Pediatric research. 2010;68(6):531-6.

10. Garca-Alix A, Quero J. Brain-specific proteins as predictors of outcome in asphyxiated term infants. Acta paediatrica. 2001;90(10):1103-5.

11. Lv H, Wang $Q$, Wu S, Yang L, Ren P, Yang Y, et al. Neonatal hypoxic ischemic encephalopathyrelated biomarkers in serum and cerebrospinal fluid. Clinica chimica acta; international journal of clinical chemistry. 2015;450:282-97.

12. Takahashi K, Hasegawa S, Maeba S, Fukunaga S, Motoyama M, Hamano H, et al. Serum tau protein level serves as a predictive factor for neurological prognosis in neonatal asphyxia. Brain \& development. 2014;36(8):670-5.

13. Thorngren-Jerneck K, Alling C, Herbst A, Amer-Wahlin I, Marsal K. S100 protein in serum as a prognostic marker for cerebral injury in term newborn infants with hypoxic ischemic encephalopathy. Pediatric research. 2004;55(3):406-12.

14. Ponnusamy V, Kapellou O, Yip E, Evanson J, Wong LF, Michael-Titus A, et al. A study of microRNAs from dried blood spots in newborns after perinatal asphyxia: a simple and feasible biosampling method. Pediatric research. 2016;79(5):799-805.

15. Looney AM, Ahearne CE, Hallberg B, Boylan GB, Murray DM. Downstream mRNA Target Analysis in Neonatal Hypoxic-Ischaemic Encephalopathy Identifies Novel Marker of Severe Injury: a Proof of Concept Paper. Molecular neurobiology. 2016.

16. Perlman M, Shah PS. Hypoxic-ischemic encephalopathy: challenges in outcome and prediction. The Journal of pediatrics. 2011;158(2 Suppl):e51-4.

17. Fiala M, Baumert M, Surmiak P, Walencka Z, Sodowska P. Umbilical markers of perinatal hypoxia. Ginekologia polska. 2016;87(3):200-4.

18. Ahearne CE, Boylan GB, Murray DM. Short and long term prognosis in perinatal asphyxia: An update. World journal of clinical pediatrics. 2016;5(1):67-74.

19. Murray DM, O'Connor CM, Ryan CA, Korotchikova I, Boylan GB. Early EEG Grade and Outcome at 5 Years After Mild Neonatal Hypoxic Ischemic Encephalopathy. Pediatrics. 2016;138(4). 
20. Stuart A, Otterblad Olausson $P$, Kallen $K$. Apgar scores at 5 minutes after birth in relation to school performance at 16 years of age. Obstetrics and gynecology. 2011;118(2 Pt 1):201-8.

1.

2.

6.

7.

9.

11.

12. Matsushige T, Ichiyama T, Kajimoto M, Okuda M, Fukunaga S, Furukawa S. Serial cerebrospinal fluid neurofilament concentrations in bacterial meningitis. Journal of the neurological sciences. 2009;280(1-2):5961.

13.

14.

15.

16.

17. 